\title{
Correction to: Inter-provincial inequality of public health services in China: the perspective of local officials' behavior
}

\author{
Tianxiang Chen ${ }^{1,2}$, Ying Wang ${ }^{1}$, Xiaoyi Luo ${ }^{3}$, Yuxuan Rao ${ }^{4}$ and Lei Hua ${ }^{1,2^{*}}$
}

\section{Correction}

Unfortunately, after publication of this article [1], it was noticed that a value in Table 2 is incorrect. In the column 'ADF-Fisher test' in the row 'd_transfer', the value displayed as 60.952 should instead read 125.781. Subsequent tests and results were based on the latter figure so this change does not affect the results and conclusions drawn.

\footnotetext{
Author details

${ }^{1}$ School of Government, Sun Yat-sen University, Guangzhou, Guangdong, China. ${ }^{2}$ Department of Public Administration, Nanfang College of Sun Yat-sen University, Guangzhou, Guangdong, China. ${ }^{3}$ School of Law and Business, College of Science and Technology of Ningbo University, Ningbo, Zhejiang, China. ${ }^{4}$ College of Liberal Art and Science, University of Illinois at Urbana-Champaign, Urbana, Illinois, USA.
}

Received: 10 August 2018 Accepted: 10 August 2018 Published online: 04 September 2018

\section{Reference}

1. Chen T, Wang Y, Luo X, Rao Y, Hua L. Inter-provincial inequality of public health services in China: the perspective of local officials' behavior. Int J Equity Health. 2018;17:108. https://doi.org/10.1186/s12939-018-0827-8.

* Correspondence: leihuapir@gmail.com; leihuapir@outlook.com

'School of Government, Sun Yat-sen University, Guangzhou, Guangdong, China

${ }^{2}$ Department of Public Administration, Nanfang College of Sun Yat-sen

University, Guangzhou, Guangdong, China

Full list of author information is available at the end of the article

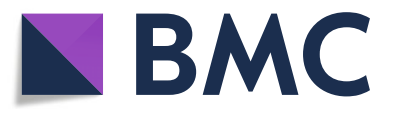

(c) The Author(s). 2018 Open Access This article is distributed under the terms of the Creative Commons Attribution 4.0 International License (http://creativecommons.org/licenses/by/4.0/), which permits unrestricted use, distribution, and reproduction in any medium, provided you give appropriate credit to the original author(s) and the source, provide a link to the Creative Commons license, and indicate if changes were made. The Creative Commons Public Domain Dedication waiver (http://creativecommons.org/publicdomain/zero/1.0/) applies to the data made available in this article, unless otherwise stated. 